\title{
Decision Making Approaches for Complex Adaptive Systems in Built Environment
}

\author{
Mei Lee
}

\author{
University of Salford, United Kingdom
}

\begin{abstract}
The decision processes in the construction industry are complex with several dimensions that have to be taken into consideration. These comprise, for instance, of the urban planning, health and safety, facilities management, and energy efficiency. The process of designing and erecting a building usually involves multiple and conflicting objectives such as cost, time, quality, resource utilization, to name a few. The decisions in addressing various aspects concerning the construction process and the sustainability of the end product are numerous and of the conflicting nature. Therefore, finding an appropriate decision making approach is the cornerstone of the effective decision process. This paper proposes the use of biomimicry and genetic algorithms as an alternative to the established practice in decision making for the complex and adaptive system in built environment.
\end{abstract}

Paper Type: Conceptual Paper

Keywords: Decision Making Approaches; Genetic Algorithms; biomimicry; complex adaptive systems; built environment; CASBE 


\section{Introduction}

The contemporary built environment is typically referred to the interdisciplinary field that involves many different stakeholders and professionals over a period of time (Ruddock, 2008). Conceptualising the built environment as a complex adaptive system would help to shed some light on how and where planners, builders, construction professionals, and policy-makers can direct their interventions to promote sustainable development (Folke et al., 2002). Therefore, the decision making process in the construction industry is often lengthy due to its complexity. Non-linear decision making approaches have been proposed for use in the construction industry, namely genetic algorithm (Juan et al., 2006; Kim and Shim, 2013; Leu et al., 2000), and biomimicry (Lurie-Luke, 2004; Kibert et al., 2000; Pedersen Zari, 2015).

Typically the subject of biomimicry reflects an understanding about resemblance between artificial objects and other living organisms that have totally different nature, for the purpose of self-protection or advantage over other organisms. Although it is inevitable and logical to link biomimicry with the meanings of 'hiding' and 'imitating', this paper discusses a step beyond this mindset. It suggests the way of applying biomimicry in the field of complex adaptive system for the built environment (CASBE) and highlights its potential applications into other areas.

Biomimicry can also be applied to decision making processes as an alternative approach by decision makers. The core concept of biomimicry is to mimic the surrounding environment or other organisms in order to survive. By extending this concept, it is noted that there are many inspirations could be drawn or borrowed from Mother Nature. Again, it is believed that the decision makers could have a clearer picture in an unknown situation by realigning their thoughts process with a biological concept.

On the other hand, Genetic Algorithms (GA) originated from the genetic science and greatly developed into the fields of the data mining and data analysis. Traditional approaches to decision making require extensive information for a situation assessment and solutions identification. However, it can be noted here that an extensive set of supplementary information is not needed where GA is used, which could save the time and effort in gathering extensive and often remotely relevant information.

The purpose of this paper is to explore the potential of Genetic Algorithms and biomimicry as decision making approaches to be adopted in the complex adaptive systems for the built environment. In the following sections, the characteristics of biomimicry and Genetic Algorithms are going to be discussed by comparing and contrasting their applications in decision making with both techniques being compared with traditional approach to decision making.

\section{Biomimicry As An Alternative Approach to Decision Making}

As it was established earlier, biomimicry is about mimicking. It is suggested here that application of the 'mimicking' concept could be applicable within the human and

International Journal of Management and Applied Research, 2017, Vol. 4, No. 4 
built environment. That is to say, any imitation of an adaptive system found in nature into the human and built environment could be done by analogy or copying its key behavioural aspects, the same apply to replication of the biological theories into the field of decision making. There are many similarities between the natural environment and built environments, but the main one is that they both evolving and adapting to the new challenges with time.

Analogy as such has been widely used in our human environment: in the field of marketing (Mascarenhas et al., 2005; Massey, 1999) or in legal environment (Schauer, 2006; Teorell, 2006), in business environment (DeRosia, 2006; Hamel, 2006), in gaming (Brindle, 1999; Kokinov, 2003), etc. The advantage of using analogy (in any field of study) is grounded into its ability to make a logical reference to a 'known' situation. As stated by Brindle (1999: 607), "by referencing a "known" situation, even if it has little to do with the real issues we are discussing, some certainty is interjected, around which we can then balance our thoughts.'

Decision makers may find the application of analogy in decision making as useful in supporting and/or opposing new proposals (Brindle, 1999: 608). By analogy with theories and history, a decision maker can then have backing up his examples to reinforce his considerations. By doing so, the decision maker would be aware of 'what to avoid' and 'what to support' aspects in the analysed situation. In the traditional approach to decision making, the process of gathering information is a very exhausting exercise. The factors to be considered include the availability and accessibility of data as well. On contrary, the availability and accessibility of information in relation to biology is unlimited and the richness of information is being augmented over time.

\section{Genetic Algorithms As An Approach to Decision Making}

On the other hand, Genetic Algorithms (GA) is a computational method that mimics biological evolution (Marczyk, 2004). GA have been applied for and within various fields of study, such as optimisation, economics, and most frequently used in problem solving (Mitchell, 1998: 16). As Simon (1986) asserts the problem solving is about designing a strategy or strategies. After the strategies are formulated, the next step would be in evaluating and choosing of the most appropriate one, which is generally known as decision making (ibid). The process of decision making is thus a process of searching for the 'best' solution, which is quite similar to the process of evolution. Mitchell (1998: 4) states that 'evolution is, in effect, a method of searching among an enormous of possibilities for "solution".'

The advantages of using GA, especially in problem solving and optimisation of solutions, include the multiple optimum solutions instead of one, blindness to auxiliary information, exploration of the solution space in multiple directions simultaneously (Goldberg, 1989; Haupt and Haupt, 1998; Marczyk, 2004). In relation to that, it is believed here that application of GA in decision making is useful for decision makers in searching the optimal solution. In other words, the use of GA

International Journal of Management and Applied Research, 2017, Vol. 4, No. 4 
enables decision makers to uncover optimal solutions that might never be encountered by following human's intuition. So, how it could be achieved?

Marczyk (2004) reports that 'unlike GA, [traditional approaches to decision making] are usually mathematically guaranteed to deliver the one exact solution.' This implies that GA, as stated above, provides more than one solution for decision makers to choose. Therefore, decision makers could have more options to take into account and weight up the 'best' solution as a whole o comprehensive one. However, the higher number of solutions than the more powerful is the GA, as its weakest point is its strength at the same time. Therefore, when the situation is not too problematic, GA may perform slower than the traditional approaches to decision making (Haupt and Haupt, 1998: 18).

Additionally, as noted by Goldberg (1989: 9) 'GA has no need for all auxiliary information: GA is blind. To perform an effective search for better and better structures, they only require payoff values (objective function values) associated with individual strings'. This indicates that GA works with available information for computing an optimal solution, which could provide an optimal solution with a lesser effort. Moreover, any supplementary information, which is essential for other methods, is not that important in GA.

Unlike traditional approaches, GA work 'from a population...instead of a single point' (Goldberg, 1989: 23). Some steps in traditional approach to decision making are omitted where GA is applied in decision making, such as identification of critical factors involved in a decision, recording of what is known about each factor, developing questions for what is not known about each factor, identifying resources for fact-finding and completing fact-finding.

\section{Biomimicry versus Genetic Algorithms}

Notably, both these alternative to traditional approaches in decision making are inspired by the evolving and adaptive natural systems. The significant difference between these two techniques is that, GA exploits competition among populations as computations in maximising accuracy of solution whereas biomimicry sees it as a lesson. In GA, the survival of fittest is seen as 'replacing the weakest candidates' and ultimately produce the 'fittest' solution. In other words, GA 'process similarities in the underlying coding together with information ranking the structures according to survival capability in the current environment.' (Goldberg, 1989: 23) On the contrary, the specialities of 'fittest' as well as the features of 'extinct' are noticed and taken as a lesson in the application of biomimicry. Next, the similarities of biological metaphors and current situation are identified and the possible outcomes are assessed. By doing so, it provides a valid reason to support or to reject a solution (or a proposal).

This leads to another distinctive difference between GA and biomimicry. GA heavily relies on quantitative facts and data, but such numerical facts and statistics are not the major concerns in biomimicry. That is to say that GA is more systematic and mathematical based while the in-depth knowledge regarding the 'fittest' organism is ignored in GA, such as the good track of survivability records. And this leads Goldberg (1989: 9) to conclude that 'GA is blind'.

International Journal of Management and Applied Research, 2017, Vol. 4, No. 4 
On the other hand, the longer is the time allowed for evaluation, the higher is the degree of accuracy of the results obtained in the application of GA. In relation to that, time needed for GA in computing the optimal solution varies accordingly to the degree of accuracy and time allowed for evaluation. In other words, it is a trade off between 'speed' and 'accuracy'. When little time is allowed for the application of GA, it is more suitable to find an 'adequately' accurate result. As a result, the degree of accuracy will be slightly decreased yet it will not be too remote from the 'perfectly' accurate results.

Similarly, a time needed for making decision by using biomimicry varies, but the reason behind is different. In biomimicry, the time needed depends on the ability of decision maker to track for the similarities between the current situations with biomimicry and to apply the identified likeness for the purpose of decision making. Further, there is no standard measurement on determining the level of accuracy of biomimicry in this case. Perhaps, the accuracy in this context should be replaced by acceptability, i.e. the analogy has to be acknowledged and to be familiar to the audience, such as management, clients or readers. In relation to that, the time needed for a decision maker, who adopts biomimicry, is open to a greater level of subjectivity.

\section{Potential Applications for non-traditional Techniques}

Genetic Algorithms and Biomimicry have a high number of potential applications. This statement could be explained by the fact that GA in particular has direct implications for the decision making. They are particularly applicable in strategic decision making, as they require time to develop and exploit potential strengths of the crossover, mutation and inversion. Decision making as a domain of the rational logic is essential for any area of the natural and especially social sciences. For instance, it could be applied in the fields of neural networks, machine learning and evolutionary computation.

Similarly, GA could be successfully employed for some business applications as indicated by Grupe and Jooste (2004: 297): bankruptcy prediction; control design; currency demand analysis; fraud detection; interest earnings maximization; identification of money laundering; plant layout; portfolio optimisation; process control; risk analysis; space allocation for Return Of Investment (ROI); supply chain optimisation; resource allocation; data modelling and analysis; stock market risk analysis; broker surveillance; routing; sports event attendance prediction; complex equipment design; job shop scheduling; signal processing; vehicle scheduling; worker scheduling; and job schedule development.

On the other hand, the biological concept has been widely citied by management, business analyst, marketing strategists, and academic researchers. It is noted here, both techniques could be applied into the field of built environment and society.

International Journal of Management and Applied Research, 2017, Vol. 4, No. 4 


\section{1. Applications to the field of Built Environment}

Janine Benyus has suggested mimicking the special characteristics of organism in designing building materials (Biomimicry, 2016). By doing so, designers could have a lively framework to scrutinise and then imitate and apply the concepts into designing building material. According to her, the natural system should be seen as a model to learn and to mimic. By seeing the nature as a learning model, more sustainable solutions and designs can then be developed.

On the other hand, the scheduling of building maintenance will be made by applying GA. Application of GA in scheduling is not a new concept, its applications include: job shop scheduling procedure (Davis, 1985, citied by Goldberg, 1989), schedule optimisation (Syswerda, 1991), concrete sleepers production scheduling (PérezVázquez et al. 2004), flight schedule planning (Adachi et al. 2004). However, it is noted that the application of GA in maintenance field is almost an untouched area. Building maintenance is a complex set of operations - it involves technical, social, legal and fiscal determinants that govern the use of the building. In general, the life span of a building is expected to be 60 years and up to 100 years. The principle behind maintaining a building is about extending its useful lifecycle. Basically maintenance works can be divided into two groups: planned works and unplanned works. Planned works which are scheduled on maintaining the building can be estimated from past records and current knowledge of the building's condition. Contrary, unplanned works can be defined as urgent maintenance works (e.g. repairs, replace or demolish) which are statistically estimated based on estimation of potential failures. In short, building maintenance management is about managing risk as budget or timetable. Despite there are many tools to monitor and manage timetable for inspection of building, is noted here that these tools are insufficient to deliver an optimal timing for inspection. This suggests a need for a method for designing solutions for complex problems. Thus, it is suggested here to apply GA into the field of building maintenance.

\subsection{Applications to the Society}

On the personal note, it can be noted that GA and Biomimicry are applicable to life of society or individuals. For example, using a society as a field application of GA, it could be seen that democracy as a kind of selection, with attempt to choose a 'fittest' solution. The quest for power between political parties can be seen as a kind of crossover. Finally, a leadership challenge within any party would illustrate mutation.

On other hand, an application of Biomimicry in the same example a society would help to forecast the range of events, such as decline of firms within a specific industry in a particular geographic area. Therefore, it would have the direct implications for risks or potential development or investments analysis. Again, it is inferred that for example 'struggle for existence' could serve as a basis for analysing of the success or failure for individual enterprise if such parameters as individual performance, market demand, cost factors and logistics are taking into consideration.

International Journal of Management and Applied Research, 2017, Vol. 4, No. 4 


\subsection{Strengths and Weaknesses of Each Technique for the Identified Applications}

The outlined above potential applications of Genetic Algorithms and Biomimicry have associated with them strengths and weaknesses. Firstly, it has to be mentioned that both techniques require time to exhibit or utilise the inherit potency. In the case of many business applications mentioned above, time in general or reaction time in particular is a crucial variable. Therefore, application of the GA and Biomimicry within limited time frame may not bring a positive result or even might be harmful. This leads to the second weakness, common for both techniques. It is absence of linearity or clearly seen the cause and effect relationships, which are considered to be vital for many modern business applications. The vast majority of management literature emphasises clear and rational casual relationships in a case of any important decision. Therefore, especially in the case of GA, when a certain time is needed for crossover, mutation or inversion, the clear cause and effect relations of related decisions could be very fuzzy in short terms. This goes across so called 'management logic' that favours short term centred judgments: long terms goals are sacrificed in favour of short term achievements.

Moreover, the application of GA requires specialised skills in programming and statistics in order to develop the process of GA and interpret the results (Grupe and Jooste, 2004). Despite there are software products incorporate GA components available on the marketplace, the interpretation of results obtained in GA requires a high level of proficiency in a quantitative analysis. As stated by Mitchell (1998: 156), 'A GA's performance will depend very much on details such as the method for encoding candidate solutions, the operators, the parameter settings, and the particular criterion for success'.

It is believed the applying GA into the field of building maintenance management is a fruitful area as it is likely to make the budget and timetable more manageable. As indicated by Haupt and Haupt (1998: 17), 'GA works with numerically generated data, experimental data, or analytical functions.' Therefore, the past records and current information about the building conditions could be exploited in evaluating the time and costs needed in maintaining the building conditions. Table 1 summarises the strengths and weaknesses of GA.

Table 1: Strengths and Weaknesses of Genetic Algorithms

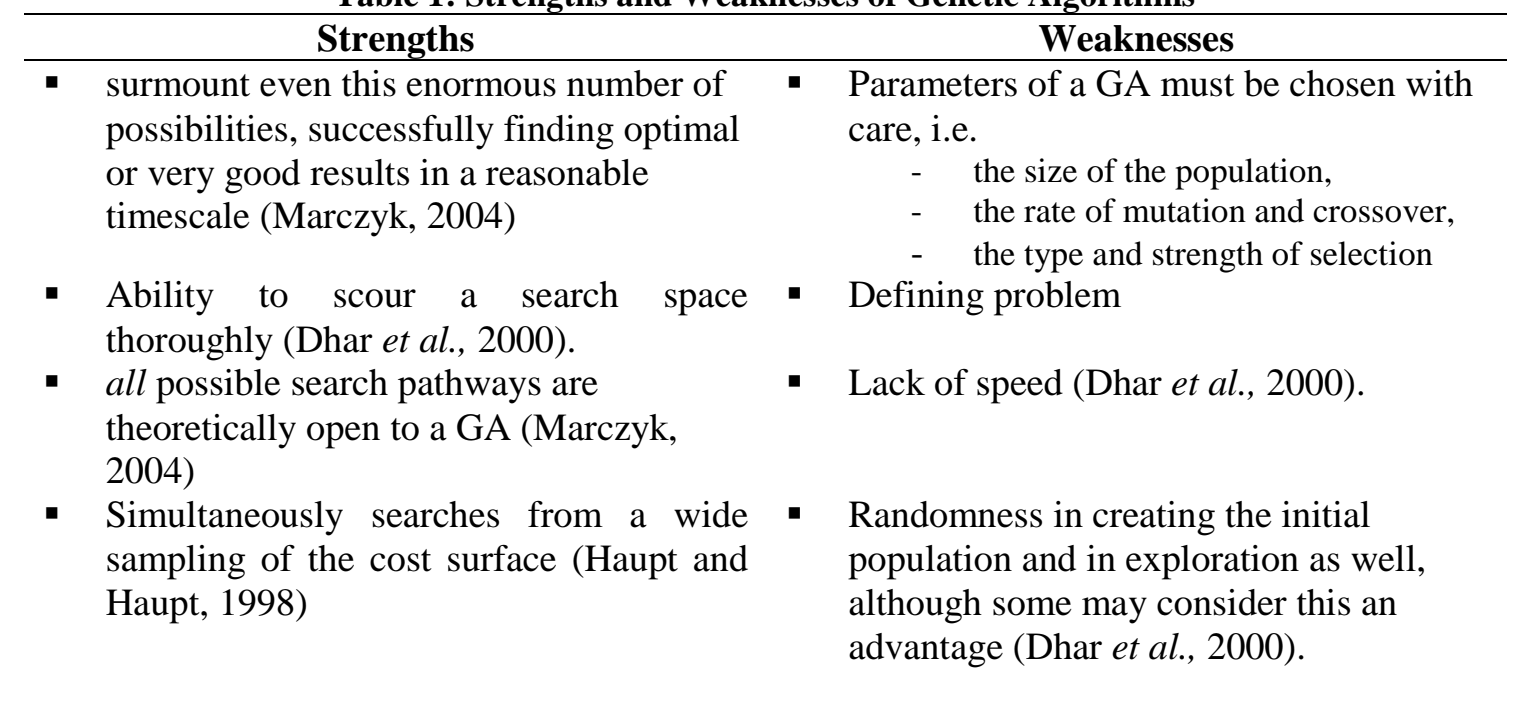

International Journal of Management and Applied Research, 2017, Vol. 4, No. 4 
- Ability to allow arbitrary fitness functions in the search (Dhar et al., 2000).

- Reliably predict national opinion while sampling only a small percentage of the population (Marczyk, 2004)

- Optimises with continuous or discrete parameters (Haupt and Haupt, 1998: 17)

- Works with numerically generated data, experimental data, or analytical functions (Haupt and Haupt, 1998: 17)
- Use of language

- Myopic after they find one good solution (Dhar et al., 2000).

- Formulating fitness function

On the other hand, mimicking the special features of biological organisms as a design model has an advantage of accessing information as there are infinite numbers of insightful organisms are available that would enable designers to mimic their characteristics. The problem here is that, the information available for designing has not been translated into the form of assimilation. Table 2 summarises the strengths and weaknesses of biomimicry.

Table 2: Strengths and Weaknesses of Biomimicry

\begin{tabular}{|c|c|}
\hline Strengths & Weaknesses \\
\hline $\begin{array}{l}\text { - Allows continuous observations to the } \\
\text { biological metaphors used }\end{array}$ & $\begin{array}{l}\text { Difficult to spot the similarities between } \\
\text { biological concept and current situation } \\
\text { - Difficult to translate the language used in } \\
\text { biological concept into potential } \\
\text { application }\end{array}$ \\
\hline
\end{tabular}

\section{Conclusion}

In the filed of built environment there are various tools and techniques to help the decision makers to formulate a sensible and rational decision. These include linear programming, optimisation, simulation, etc. The alternative techniques, such as biomimicry and Genetic Algorithms (GA), are exceedingly helpful for decision makers in making sensible judgement.

The emphasis of any technique used in decision making is on its accuracy, reliability and validity. In this context, both GA and biomimicry are able to provide a valid and reliable suggestion for a decision maker, and in addition, GA offers a solution that is nearly perfect in accuracy. Defining the level of accuracy in biomimicry may not be viable and thus it is suggested here to replace it with 'acceptability' in the application of biomimicry. In relation to that, the 'acceptability' in biomimicry depends on the capability of the decision maker for the deducing thinking, which is considerably subjective. However, the strategy proposed by each technique merely serve as a template, the ultimate decision still lies on the intuition of decision maker.

Biomimicry and Genetic Algorithms have a great number of potential applications, including the problem solving for the society and the built environments. The greatest challenges to both techniques are the time allowance and assimilation of information as well as interpretations of results, especially where GA is applied. Gathering information is not a limitation for these techniques. As Mother Nature is open to us

International Journal of Management and Applied Research, 2017, Vol. 4, No. 4 
for scrutiny and mimic, the availability of information is not a constraint where biomimicry is used. Further, as 'GA is blind' (Goldberg, 1989: 9), GA is still able to provide optimal solutions where necessary information is not available.

To conclude, both techniques are exceedingly powerful if the outlined associated problems are neutralised or mitigated for. It appears that application of both techniques is quite challenging, but nevertheless it is rewarding, especially when any traditional approach fails to deliver a sensible outcome.

\section{References}

1. Adachi, N. Sato, M. and Kobayashi, S. (2004), “Application of genetic algorithm to flight schedule planning", Systems and Computers in Japan, Vol. 35, No. 12, pp. 83 - 92. https://doi.org/10.1002/scj.10036

2. Biomimicry (2016) What is Biomimicry? [Online] Available from: https://biomimicry.net/what-is-biomimicry/ [Accessed 3 November 2017].

3. Brindle, M. (1999), "Games decision makers play", Management Decision. Vol. 37, No. 8, pp. 604-612. https://doi.org/10.1108/00251749910291569

4. DeRosia, E. D. (2006), “Civil Metaphor”, Marketing Research, Vol. 18, No. 1, pp. $8-13$.

5. Dhar, V., Chou, D. and Provost, F. (2000), "Discovering Interesting Patterns in Investment Decision Making with GLOWER - A Genetic Learning Algorithm Overlaid With Entropy Reduction", Data Mining and Knowledge Discovery, Vol. 4, No. 4, pp 251-280, https://doi.org/10.1023/A:1009848126475

6. Folke, C.; Carpenter, S.; Elmqvist, T.; Gunderson, L.; Holling, C. S. and Walker, B. (2002), "Resilience and Sustainable Development: Building Adaptive Capacity in a World of Transformations", AMBIO: A Journal of the Human Environment, Vol. 31, No. 5, pp. 437-440. https://doi.org/10.1579/0044-7447-31.5.437

7. Goldberg, D. E. (1989), Genetic algorithms in search, optimization, and machine learning. Reading: Addison-Wesley.

8. Grupe, F. H. and Jooste, S. (2004), "Genetic algorithms: A business perspective", Information Management \& Computer Security, Vol. 12, No. 3, pp. 288-297. https://doi.org/10.1108/09685220410542624

9. Hamel, G. (2006), “The Why, What, and how of Management Innovation”, Harvard Business Review, Vol. 84, No. 2, pp. 72-84.

10. Haupt, R. L. and Haupt, S. E. (1998), Practical genetic algorithms. New York: John Wiley \& Sons, Inc.

International Journal of Management and Applied Research, 2017, Vol. 4, No. 4 
11. Juan, Y. K.; Shih, S. G. and Perng, Y. H. (2006), "Decision support for housing customization: A hybrid approach using case-based reasoning and genetic algorithm", Expert Systems with Applications, Vol. 31, No. 1, pp. 83-93, https://doi.org/10.1016/j.eswa.2005.09.010.

12. Kibert, C. J.; Sendzimir, J. and Guy, B. (2000), "Construction ecology and metabolism: natural system analogues for a sustainable built environment", Construction Management and Economics, Vol. 18 , No. 8, pp. 903-916, https://doi.org/10.1080/014461900446867

13. Kim, S. and Shim, J. H. (2014), "Combining case-based reasoning with genetic algorithm optimization for preliminary cost estimation in construction industry", Canadian Journal of Civil Engineering, Vol. 41, No. 1, pp. 65-73, https://doi.org/10.1139/cjce-2013-0223

14. Kokinov, B. (2003), “Analogy in decision-making and social interaction and emergent rationality”, Brain and Behavioral Sciences, Vol. 26, No.2, pp. 167-168. https://doi.org/10.1017/S0140525X03370050

15. Leu, S. S.; Yang, C. H. and Huang, J. C. (2000), "Resource leveling in construction by genetic algorithm-based optimization and its decision support system application", Automation in Construction, Vol. 10, No. 1, pp. 27-41, https://doi.org/10.1016/S0926-5805(99)00011-4.

16. Lurie-Luke, E. (2014), "Product and technology innovation: What can biomimicry inspire?", Biotechnology Advances, Vol. 32, No. 8, pp. 1494-1505.

https://doi.org/10.1016/j.biotechadv.2014.10.002

17. Marczyk, A. (2004), Genetic Algorithms and Evolutionary Computation. [Online] The Talking Origins Archives. Available from:

http://www.talkorigins.org/faqs/genalg/genalg.html\#limitations [Accessed 30 November 2017].

18. Mascarenhas, O. A., Kesavan, R., Bernacchi, M. (2005), "Global marketing of lifesaving drugs: an analogical model", Journal of Consumer Marketing, Vol. 22, No. 7, pp. 404-411. https://doi.org/10.1108/07363760510631147.

19. Massey, G. R. (1999), "Product evolution: a Darwinian or Lamarckian phenomenon?", Journal of Product \& Brand Management, Vol. 8, No. 4, pp. 301-318. https://doi.org/10.1108/10610429910284292

20. Pedersen Zari, M. (2015), "Can Biomimicry Be a Useful Tool for Design for Climate Change Adaptation and Mitigation?", In: Pacheco Torgal F., Labrincha J., Diamanti M., Yu CP., Lee H. (eds), Biotechnologies and Biomimetics for Civil Engineering. Cham: Springer, pp. 81-113. https://doi.org/10.1007/978-3-319$\underline{09287-4 \_4}$ 
21. Pérez-Vázquez, M. E., Gento-Municio, A. M. and Ramalhinho-Lourenço, H. (2004) "Solving a Concrete Sleepers Production Scheduling by Genetic Algorithms", In: Economics Working Papers, No. 736. Barcelona: Universitat Pompeu Fabra.

22. Ruddock, L. (2008), Economics for the Modern Built Environment, UK: Routledge.

23. Schauer, F. (2006), “Do Cases Make Bad Law?”, Law Review. Vol. 73, No. 3, pp. 883.

24. Simon, H. A. and Associates (1986), Decision Making and Problem Solving. [Online] Washington, DC: National Academy Press. Available from: http://dieoff.org/page163.htm [Accessed 22 November 2017].

25. Syswerda, G. (1991), "Schedule optimization using genetic algorithms", In: Davis, L. (ed) Handbook of Genetic Algorithms, New York: Van Nostrand Reinhold pp. 332--349.

26. Teorell, J. (2006), "Political participation and three theories of democracy: A research inventory and agenda", European Journal of Political Research, Vol. 45, No. 5, pp. 787-810. https://doi.org/10.1111/j.1475-6765.2006.00636.x 